\title{
Inorganic Particle Analysis of Dental Impression Elastomers
}

\author{
Hugo Lemes CARLO ${ }^{1}$ \\ Rodrigo Borges FONSECA ${ }^{2}$ \\ Carlos José SOARES ${ }^{3}$ \\ Américo Bortolazzo CORRER ${ }^{4}$ \\ Lourenço CORRER-SOBRINHO ${ }^{4}$ \\ Mário Alexandre Coelho SINHORETI ${ }^{4}$
}

\author{
${ }^{1}$ Department of Restorative Dentistry, Health Sciences Center, Federal University of Paraiba, João Pessoa, PB, Brazil \\ ${ }^{2}$ Department of Oral Rehabilitation, Dental School, Federal University of Goiás, Goiânia, GO, Brazil \\ ${ }^{3}$ Dental School, Operative Dentistry and Dental Materials Division, \\ Federal University of Uberlândia, Uberlândia, $M G$, Brazil \\ ${ }^{4}$ Piracicaba Dental School, Department of Restorative Dentistry, Dental Materials Division, \\ University of Campinas, Piracicaba, SP, Brazil
}

\begin{abstract}
The aim of this study was to determine quantitatively and qualitatively the inorganic particle fraction of commercially available dental elastomers. The inorganic volumetric fraction of two addition silicones (Reprosil Putty/Fluid and Flexitime Easy Putty/Fluid), three condensation silicones (Clonage Putty/Fluid, Optosil Confort/Xantopren VL and Silon APS Putty/Fluid), one polyether (Impregum Soft Light Body) and one polysulfide (Permlastic Light Body) was accessed by weighing a previously determined mass of each material in water before and after burning samples at $600^{\circ} \mathrm{C}$, during $3 \mathrm{~h}$. Unsettled material samples were soaked in acetone and chloroform for removal of the organic portion. The remaining filler particles were sputter-coated with gold evaluation of their morphology and size, under scanning electron microscopy (SEM). Flexitime Easy Putty was the material with the highest results for volumetric particle fraction, while Impregum Soft had the lowest values. Silon 2 APS Fluid presented the lowest mean filler size values, while Clonage Putty had the highest values. SEM micrographs of the inorganic particles showed several morphologies - lathe-cut, spherical, sphericallike, sticks, and sticks mixed to lathe-cut powder. The results of this study revealed differences in particle characteristics among the elastometic materials that could lead to different results when testing mechanical properties.
\end{abstract}

Key Words: Dental impression materials, scanning electron microscopy, filler.

\section{INTRODUCTION}

Making impressions to duplicate oral conditions and tooth morphology and constructing casts or models in gypsum are important steps in numerous prosthetic dentistry procedures $(1,2)$. In order to produce an accurate impression, the materials should be fluid enough to seep around the oral tissues and viscous enough to remain contained in the tray. They should set into a rubbery solid within a reasonable amount of time and should not distort or tear when removed from the mouth (1).

There is a group of synthetic rubber impression materials, known as elastomers or elastomeric impression materials, which were developed during World War II due to the difficulty to obtain natural rubber. These elastomers are materials formed of molecules (polymers) that are joined to each other by crosslinking in a process known as polymerization (1). According to the polymer composition, there are three kinds of dental elastomers: polysulfide, polyether and cured silicones (1-3).

Silicone materials are classified as condensation or addition silicones, depending on the reaction that produces polymerization $(1,3,4)$. Condensation-cured materials are also known as polysiloxanes as they have alternating atoms of oxygen and silicone. They are

Correspondence: Prof. Dr. Mário Alexandre Coelho Sinhoreti, Faculdade de Odontologia de Piracicaba, Área de Materiais Dentários, Avenida Limeira, 901, Caixa Postal 52, 13414-903 Piracicaba, SP, Brasil. Tel: +55-19-2106-5374. Fax: 55-19-3421-0144. e-mail: sinhoret@fop.unicamp.br 
all two-component systems with a base and a catalyst paste. The base consists of siloxane and inorganic particles while the catalyst paste contains alkylsilicate and a tin-based activator. Setting occurs by crosslinking between the terminal hydroxyl groups and the alkyl, which produces alcohol as a byproduct. As alcohol is produced in the reaction, the set material distorts as it is released $(1,3)$. Addition-cured silicones are also known as polyvinylsiloxanes (PVS) or vinyl polysiloxanes. They are also two-component materials and the setting occurs by crosslinking of vynil groups in the base material with a hydride group in the catalyst paste via a platinum catalyst and there are no reaction byproducts $(1,3)$. Inorganic particles are present in both pastes normally in the form of amorphous silica to add bulk and improve the properties of the paste (5).

The presence of particles is important on the strength of both materials and determines the viscosity (1) and accuracy $(6,7)$. Craig and Sun (8) determined that there is a relationship between strain in compression and consistency as it is decreased from putty to light bodied consistency. Lu et al. (9) showed that there are differences in the mechanical properties of the impression materials correlated to their consistencies and Chen et al. (2) stated that higher filler component may increase the accuracy. The particle size is also important to be considered, as the smaller particles tend to aggregate among each other and the larger ones do not contribute to reinforcement (1).

To the best of our knowledge, no previous study has evaluated the inorganic fraction of dental elastomers, considering only the viscosities. Due to the importance of filler in the composition of impression materials, the aim of this study was to determine filler fraction and size of commercial dental elastomers. In addition, fillers were analyzed qualitatively by scanning electron microscopy (SEM) and their composition was determined by energydispersive x-ray spectroscopy (EDX).

\section{MATERIAL AND METHODS}

In the present study, we analyzed: 6 condensation silicones [Clonage Putty and Clonage Fluid (DFL, Rio de Janeiro, RJ, Brazil), Optosil P Confort and Xantopren VL Plus (Heraeus Kulzer, Hanau, Germany), Silon 2 APS Putty and Silon 2 APS Fluid (Dentsply Latin America, Petropolis, RJ, Brazil)]; 4 addition silicones [Flexitime Easy Putty and Flexitime Correct Flow (Heraeus Kulzer), Reprosil $\mathrm{A}^{+}$Putty and Reprosil $\mathrm{A}^{+}$ Light(Dentsply Latin America)]; 1 polyether [Impregum
Soft Light (3M/ESPE, AG, Seefeld, Germany)]; and 1 polysulfide [Permlastic Light Body (Kerr Corporation, Orange, CA, USA)].

The volumetric fraction, morphology, size and composition of the filler particles of the commercial brands of dental elastomers were analyzed and are described in the following sections.

\section{Volumetric Particle Fraction}

The percentage of inorganic particles by volume was determined by calculating the difference between the mass of each material tested in air and in water (Archimedes' Principle) (10).

The materials were prepared according to the manufacturers' instructions and placed in an aluminum mold. Cylindrical specimens (12-mm diameter, 20-mm high) of each material were weighed in an analytical balance (JK 180; Chyo Balance Corp., Tokyo, Japan), accurate to $0.0001 \mathrm{~g}(\mathrm{n}=5)$. The dry mass $(\mathrm{Md})$ of the material after the setting time was determined in air. In order to determine the wet mass (Mi), a receptacle and a stainless steel mesh were placed onto the balance plate, filled with distilled water, and the specimen was immersed. The volume of the specimen after setting time was measured using the equation $\mathrm{Vs}=\mathrm{Md}-\mathrm{Mi}$.

The specimens were then burned in an oven (Bravac Ltda, São Paulo, SP, Brazil) to remove the organic phase, over $3 \mathrm{~h}$ gradually increasing the temperature from room temperature to $600^{\circ} \mathrm{C}$ (this temperature was previously determined in a pilot study). The resulting inorganic material was intact and pill-shaped. The mass in air (Mp) was then measured as described above. To determine the wet mass of the particles (Mpi), the specimens were triturated with a pestle and immersed in distilled water as described previously. The specimens were triturated to destroy air filled spaces in their interior. The volume of the inorganic particles was measured using the following equation: $\mathrm{Vp}=\mathrm{Mp}-\mathrm{Mpi}$. The percentage of the inorganic phase by volume was calculated using the following equation: Inorganic particle percentage $=(\mathrm{Vp} / \mathrm{Vs}) \cdot 100$

\section{Particle Morphology and Size}

The morphology of the particles was determined by SEM micrographs. Unsettled amounts of each material $(0.5 \mathrm{~g})$ were submitted to the washing technique (11). The matrix was removed by dissolving each 
material in $5 \mathrm{~mL}$ of acetone and centrifuging for 2 $\min$ at $1,000 \mathrm{rpm}$. This process was repeated 3 times. The remaining material mass was immersed 3 times in chloroform and centrifuged as described above for further washing and elimination of the matrix. The particles were then smeared in aluminum stubs (9), sputter coated with gold/palladium in high vacuum (SCD 050; Bal-tec AG, Liechtenstein), and examined with a scanning electron microscope (JSM-5600; JEOL Ltd. Tokyo, Japan) operating at $15 \mathrm{kv}$. Images were obtained at $1,200 \times$ magnification.

SEM micrographs were imported to the ImagePro Plus 4.5 image analyzer software (Media Cybernetics Inc., Bethesda, MD, USA) and analyzed using the measurement tool. At least 20 particles of each material were analyzed during this procedure, determining the maximum, minimum and mean diameter size. Fillers' size was determined in micrometers $(\mu \mathrm{m})$.

\section{Particle Composition}

Particle composition was determined using the powder obtained in the previous test by EDX. The particles were smeared in acrylic resin stubs, carbon coated (Denton Vacuum Desk II Sputtering; Denton Vacuum, Cherry Hill, NJ, USA), and then observed in a SEM/EDX integrated analysis system (SEM - JSM 5600; JEOL Ltd.; EDX: Vantage 1.4, Noran Instruments, Tokyo, Japan). Analyses were performed at a working distance (WD) of $20 \mathrm{~mm}, 10 \mathrm{kv}$, and variable spot size to obtain a deadtime of $20-25 \%$. For each specimen three line scan analyses of $100 \mathrm{~s}$ were performed.

\section{RESULTS}

\section{Volumetric Particle Fraction}

The mean values of percentage content of inorganic particles in volume are listed in Table 1. Flexitime Easy Putty was the material with the highest mean value (73.68\%), while Impregum Soft Light was the material with the lowest value (4.04\%). It was typically observed that materials with high viscosity (putty consistency) presented greater amount of inorganic particle than the commercially corresponding materials with low viscosity (light bodied consistency).

This is shown by the results of Clonage Putty and Clonage Fluid (47.70\% and $31.89 \%$, respectively), Flexitime Easy Putty and Flexitime Correct Flow
(73.68\% and 52.03\%), Optosil P Confort and Xantopren VL Plus (24.74\% and $23.45 \%$ ), Reprosil $\mathrm{A}^{+}$Putty and Reprosil $\mathrm{A}^{+}$Light (32.66\% and 29.04\%), and Silon 2 APS Putty and Silon 2 APS Fluid (48.25\% and $35.73 \%$ ). Generally, it was observed that the addition cured silicones presented greater amount of fillers than condensation cured silicones when using the same classification of consistency (high viscosity or low viscosity), except for Reprosil silicone that presented filler fraction similar to condensation silicones. Polyether material showed the lowest amount of inorganic particle.

\section{Particle Morphology and Size}

The morphology of the particles is shown in the SEM micrographs presented as Figures 1 and 2. The materials particles had the appearance of lathe-cut powder, spherical objects, spherical-like objects, and sticks, which seemed to be a junction of various circular and perforated objects with a central hole and variable length and diameter. It was not possible to eliminate the polymeric matrix from Xantopren VL Plus even after dissolving each material over one week in acetone and chloroform. Also, it was still possible to see remaining portions of the polymeric matrix adjacent to the spherical fillers of Clonage Putty.

The maximum, minimum and mean length (for lathe-cut shape) or diameter (for spherical shape) values

Table 1. Mean values for volumetric particle fraction (\%).

\begin{tabular}{lc}
\hline Material & Volumetric filler fraction \\
\hline Clonage Putty & 47.70 \\
Clonage Fluid & 31.89 \\
Flexitime Easy Putty & 73.68 \\
Flexitime Correct Flow & 52.03 \\
Optosil P Confort & 24.74 \\
Xantopren VL Plus & 23.45 \\
Reprosil A ${ }^{+}$Putty & 32.66 \\
Reprosil A+ Light & 29.04 \\
Silon 2 APS Putty & 48.25 \\
Silon 2 APS Fluid & 35.73 \\
Impregum Soft Light & 4.04 \\
Permlastic Light Body & 39.35 \\
\hline
\end{tabular}


of the inorganic particles are listed in Table 2. Clonage Putty showed the highest values $(27.75 \mu \mathrm{m})$, while Silon 2APS presented the lowest values $(4.60 \mu \mathrm{m})$. Because of the difference in the particle shape of Reprosil $\mathrm{A}^{+}$ Putty, Reprosil $\mathrm{A}^{+}$Light and Impregum Soft Light, which showed a considerable length to be measured, Table 2 presents their maximum, minimum and mean length values. It was not possible to measure the filler size of Xantopren VL Plus because of the difficulty to eliminate the polymeric matrix.
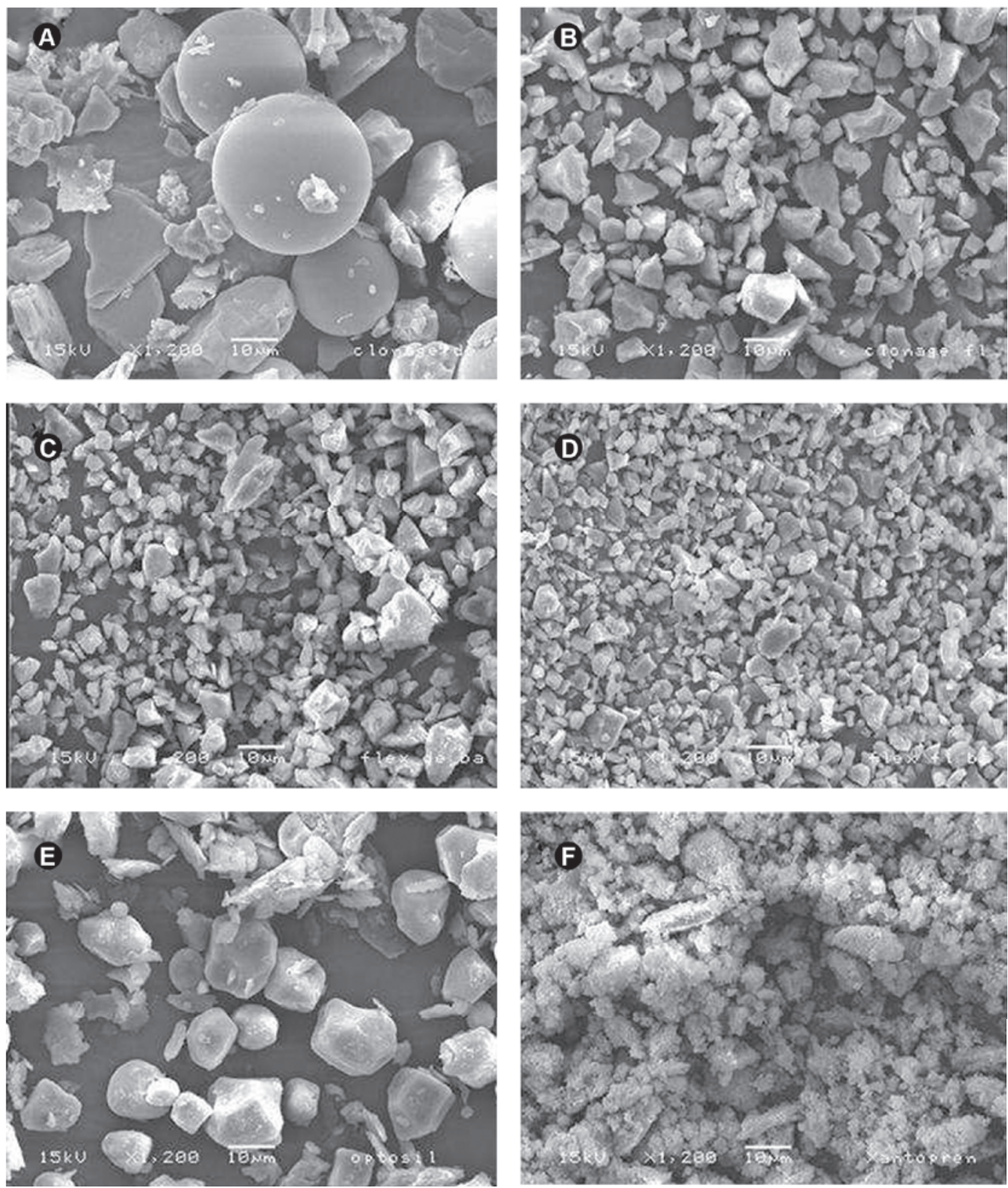

Figure 1. Panel of SEM micrographs of elastomeric materials $(1,200 \times)$. A= Clonage Putty: large and spherical glass particles can be seen mixed with large lathe-cut particles; $\mathrm{B}=$ Clonage Fluid: lathe-cut particles can be seen, but smaller than in putty consitency; $\mathrm{C}=$ Flexitime Easy Putty: the material presents small lathe-cut particles mixed with larger particles of the same type; $\mathrm{D}=\mathrm{Flexitime}$ Fluid: the fluid consistency of the Flexitime also presents lathe-cut particles, but only in smaller size; E= Optosil Confort: can be seen large vitreous particles with spherical-like form; $F=$ Xantopren: it was not possible to completely eliminate the polymeric matrix to visualize the fillers, but the image suggests the presence of lathe-cut particles. 


\section{Particle Composition}

Results for particle composition by EDX analysis are listed in Table 3. Silicon (Si) was the component with highest concentration in the materials. In general the composition was the same for all materials with the presence of $100 \%$ Si composition. Clonage Putty presented Zinc ( $\mathrm{Zn}), \mathrm{Si}$, Calcium (Ca), and Indium (I). Optosil P Confort presented Zn, Magnesium (Mg),
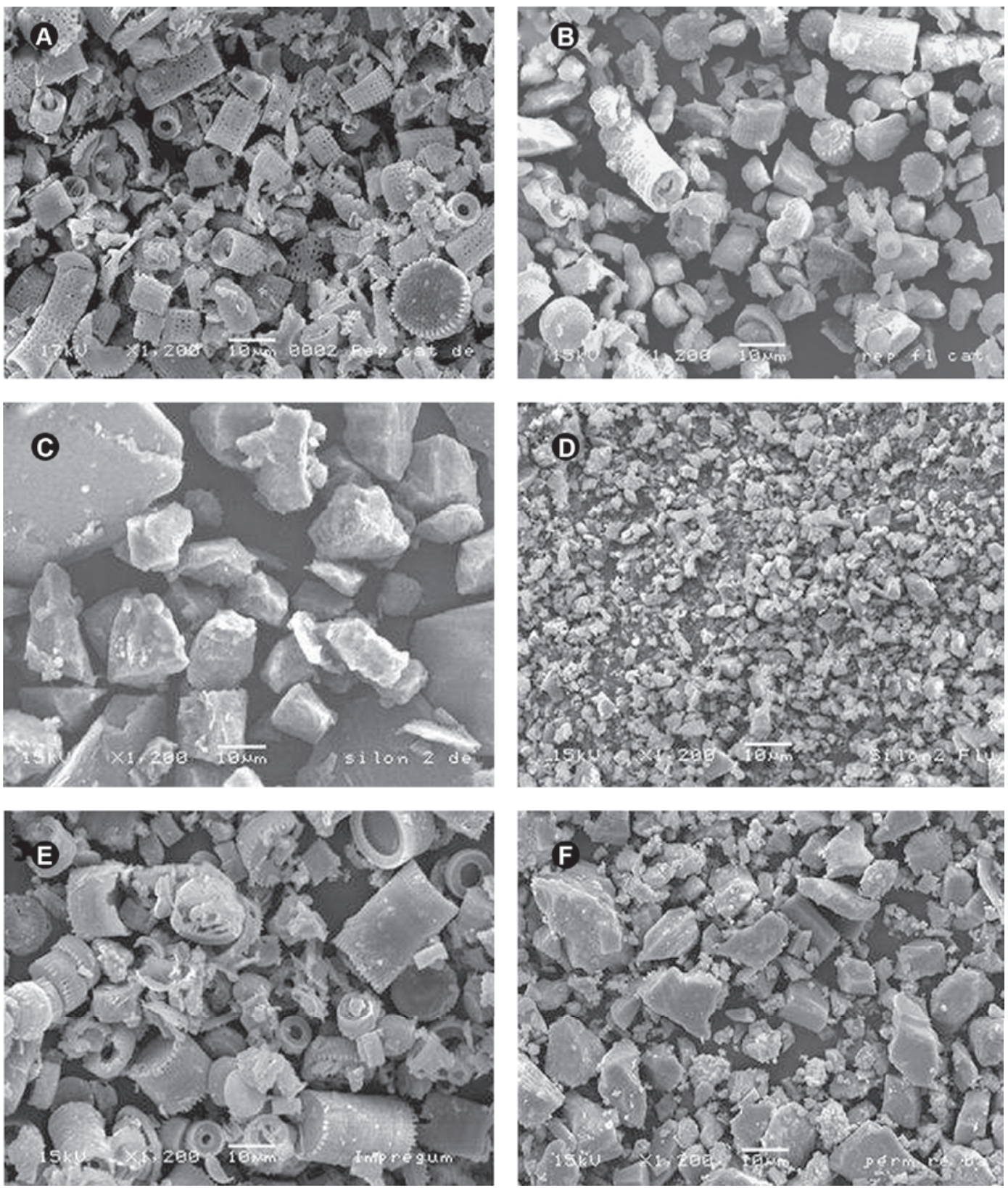

Figure 2. Panel of SEM micrographs of elastomeric materials $(1,200 \times)$. A= Reprosil A+ Putty: Diatomite particles can be seen with several shapes and sizes, predominating cylindrical and perforated sticks; $\mathrm{B}=$ Reprosil A+ Regular: cylindrical diatomite particles can be seen mixed with big lathe-cut particles; $C=$ Silon 2APS Putty: large particles with irregular form can be seen; $D=$ Silon 2 APS Fluid: the fluid consistency of Silon 2 APS presents small lathe-cut particles; and, E= Impregum Soft Light: Diatomite particles can be seen with several shapes and sizes, with a circular, cylindrical or helical structure presenting various perforations, and; $F=$ Permlastic Light Body: large lathe-cut particles can see mixed with smaller particles. Residues of the polymeric matrix can also be seen. 
$\mathrm{Si}$, and Sodium (Na). Impregum Soft and Reprosil $\mathrm{A}^{+}$ presented Zn, Germanium (Ge), Aluminum (Al), Si, Ca, and Antimony (Sb).

\section{DISCUSSION}

The viscosity of impression materials is determined, in part, by the amount of particles $(2,5)$ and the findings of this investigation showed that materials with high viscosity (putty consistency) presented greater amount of inorganic filler than the commercially corresponding materials with low viscosity (medium or light bodied consistency), as it was seen for Clonage (putty/fluid), Flexitime (putty/fluid), and Silon (putty/ fluid). This also occurred with Reprosil (putty/fluid) and Optosil/Xantopren, although the percentage of fillers between high and low viscosity materials does not seem to determine effectively the consistency of the materials. It seems that the manufacturers of these products use plasticizers to control it. Another fact to be considered is that the inorganic filler composition or polymeric matrix may have some influence on the material flow. Reprosil light consistency differs from Reprosil putty due to the presence of stick fillers mixed to lathe-cut fillers. The different composition of the filler could be related to the difference in material consistency (putty/fluid). It was not possible to determine if Optosil and Xantopren fillers differ from each other, but the impossibility to remove

Table 2. Maximum, minimum and mean values for particle size $(\mu \mathrm{m})$ of the evaluated materials.

\begin{tabular}{lccc}
\hline Material & Maximum & Minimum & Mean \\
\hline Clonage Putty & 36.81 & 17.69 & 27.75 \\
Clonage Fluid & 15.68 & 3.62 & 8.91 \\
Flexitime Easy Putty & 15.48 & 4.29 & 8.44 \\
Flexitime Correct Flow & 10.55 & 3.29 & 5.53 \\
Optosil P Confort & 18.46 & 5.63 & 11.66 \\
Xantopren VL Plus & --- & --- & --- \\
Reprosil A ${ }^{+}$Putty & 24.04 & 5.47 & 10.43 \\
Reprosil A ${ }^{+}$Light & 18.50 & 3.29 & 9.69 \\
Silon 2 APS Putty & 22.24 & 9.64 & 15.13 \\
Silon 2 APS Fluid & 7.56 & 2.73 & 4.60 \\
Impregum Soft Light & 22.60 & 4.50 & 12.76 \\
Permlastic Light Body & 17.76 & 2.25 & 10.91 \\
\hline
\end{tabular}

silicone rubber matrix from Xantopren may indicate that there are differences on the linkage between fillers and matrix or matrix composition influencing on viscosity.

There is a correlation between some properties of the elastomeric impression materials and particle fraction $(2,8,9,12)$ as the consistency decreases from putty to heavy, medium or light bodied materials (5, 8 ). It is obviously because less amount of polymeric matrix is present in the composition of the materials (1). Several authors $(2,8,9,13)$ have shown that material and consistency had a significant influence on elastic recovery, permanent deformation, strain in compression, tear energy, tensile strength, thermal expansion, and dimensional stability. The light bodied materials had lower elastic recovery than the heavy bodies materials (9). Higher strain in compression values indicate more flexibility. In the present study, the putty or heavy bodied materials were stiffer than the light bodied materials $(8,9,14)$. Furthermore, heavy bodied impression materials have been shown to have higher tear resistance than those with light body consistency (9). The tensile

Table 3. Composition of the materials particles by EDX analysis.

\begin{tabular}{lc}
\hline Material & Composition (\%) \\
\hline Clonage Putty & $\mathrm{Zn}(11.92), \mathrm{Si}(68.3)$, \\
Clonage Fluid & $\mathrm{Si}(100)$ \\
Flexitime Easy Putty & $\mathrm{Si}(100)$ \\
Flexitime Correct Flow & $\mathrm{Si}(100)$ \\
& $\mathrm{Zn}(6.39), \mathrm{Mg}(15.30)$, \\
Optosil P Confort & $\mathrm{Si}(72.89), \mathrm{Na}(5.42)$ \\
& --- \\
Xantopren VL Plus & $\mathrm{Zn}(2.14), \mathrm{Ge}(0.86)$, \\
& $\mathrm{Al}(1.23), \mathrm{Si}(89.4), \mathrm{Ca}$ \\
Reprosil A ${ }^{+}$Putty & $(1.83), \mathrm{Sb}(4.54)$ \\
& $\mathrm{Zn}(2.34), \mathrm{Ge}(1.2), \mathrm{Al}$ \\
Reprosil A ${ }^{+}$Light (diatomite) & $(1.29), \mathrm{Si}(88.5), \mathrm{Ca}$ \\
& $(1.58), \mathrm{Sb}(5.21)$ \\
Reprosil A ${ }^{+}$Light (lathe-cut filler) & $\mathrm{Si}(100)$ \\
Silon 2 APS Putty & $\mathrm{Si}(100)$ \\
Silon 2 APS Fluid & $\mathrm{Si}(100)$ \\
Impregum Soft Light & $\mathrm{Al}(2.55), \mathrm{Si}(82.2), \mathrm{Ca}$ \\
& $(100)$ \\
\hline &
\end{tabular}


strength has been found to be higher for the heavy bodied materials than for the light bodied ones (9). The higher the viscosity of the impression material, the lower the thermal expansion coefficient (13). Large dimensional changes were observed for light consistency silicones compared to those with putty consistency, illustrating that the proportion of particles does modify the accuracy of the materials $(2,8)$. Based on results of this study, it is not expected from Reprosil and Optosil/Xantopren to present the correlations mentioned above because it seems that the plasticizers, particle composition, linkage between particles and matrix, and matrix composition can somehow modify the properties of these materials.

It was also observed that the addition-cured silicones and polysulfide presented larger amount of particles than the condensation-cured silicones and polyether considering the same consistency (high viscosity or low viscosity). It seems that condensationcured silicones do not allow incorporating a maximum amount of particles in the polymeric matrix as it is possible to do with the addition-cured silicones or they are supposed to display acceptable properties with less particles.

The panels of SEM micrographs of the inorganic particles (Figs. 1 and 2) showed numerous morphologies - lathe-cut, spherical, spherical-like, sticks, and sticks mixed to lathe-cut powder. Usually, colloidal silica or microsized metal oxide is added as particles (1). Particles with the lathe-cut pattern are commonly produced by grinding or milling glasses (1). Spherical particles are obtained by pyrolytic or precipitation of Si. The stick-like particles are cell walls of algae from the division Chrysophyta, class Bacillariophycea. Termed diatomaceous earth or diatomite, this material is mined and used for a variety of commercial purposes because of its worldwide range (15).

The influence of particles on the strength of a silicone elastomer is critical (1). The selection and pretreatment of the particle are of extreme importance because silicones have a low cohesive energy level and, thus, a weaker intermolecular interaction. The particles are routinely surface treated to provide better adhesion to the polymeric matrix (1). This is the reason why it was impossible to remove the polymeric matrix from Xantopren VL Plus. The linkage between particles and polymer was so tight that even after dissolving Xantopren and over a week in acetone and chloroform it was not possible to remove the silicone rubber.

The EDX analysis showed that the majority of the materials presented $100 \%$ Si composition, which seems to be the main composition of silicone rubber materials (1). Materials presenting particles with other metals in their composition - $\mathrm{Zn}, \mathrm{Ca}, \mathrm{I}, \mathrm{Mg}$ and $\mathrm{Na}$ may be those that are originated from microsized metal oxides (1). Impregum Soft and Reprosil use diatomite as filler particles. According to Bold and Wynne (15), the main element in the composition of diatomite is $\mathrm{Si}$, which has been shown to be an absolute requirement for perfect cell functioning.

Silicone impression materials are considered to be the best in reproducing surface details. The International Organization for Standardization (ISO) states that the elastomeric impression materials must reproduce lines of 75, 50 and $20 \mu \mathrm{m}$ - width according to the classification determined by the international standard (16). The size and amount of particles could be related to silicone rubber accuracy. Impregum Soft Light has diatomite as filler, which is relatively larger than the fillers of the others materials. However, as it has the lowest values of inorganic particles in volume, and thus it is expected that it would be a material with nice results for detail reproduction. Likewise, Xantopren VL Plus is the condensation silicone with the lowest values for percentage content of inorganic particles in volume. In this case, it is also expected that it would be a material with good results for reproduction of details although it is important to mention its high hydrophobic matrix and the fact that it was not possible to measure its volumetric filler fraction. Likewise, Silon 2 APS Fluid could present good results for detail reproduction because of its lower mean filler size values $(4.60 \mu \mathrm{m})$, in spite of presenting a high hydrophobic matrix as well. Permlastic Light Body also has hydrophobic matrix and filler particles of intermediate size and amount compared to other materials.

Accurate casts and models are needful in a large number of dental procedures $(1,2,17,18)$, and the volumetric filler fraction is one of the factors affecting materials properties (19). This study determined the inorganic filler fraction and quality of some commercial brands of elastomeric rubber impression materials. Further research is necessary to make a suitable correlation between particles, polymer matrix, and results for elastic recovery, strain in compression, dimensional stability, radiodensity, and detail reproduction, among other properties.

Within the limitations of the proposed analyses, the SEM images of the inorganic particles showed a 
wide range of morphologies. Flexitime Easy Putty was the material with the highest results for volumetric filler fraction, while Impregum Soft Light had the lowest values. Silon 2 APS Fluid presented the lowest mean values of filler size while Clonage Putty had the highest values. The results of this study revealed differences in particle characteristics among the tested materials that could lead to different results when testing mechanical properties.

\section{RESUMO}

O objetivo desse estudo foi determinar quantitativamente e qualitativamente a fração de partículas inorgânicas de elastômeros dentais disponíveis comercialmente. A fração volumétrica de dois silicones por adição (Reprosil Denso/Fluído e Flexitime Denso/ Fluído), três silicones por condensação (Clonage Denso/Fluído, Optosil/Xantopren, e Silon 2 APS Denso/Fluído), um poliéter (Impregum Soft Light) e um polissulfeto (Permlastic Light Body) foi determinada pela pesagem prévia de uma determinada massa de cada material em água antes e após a queima das amostras a $600^{\circ} \mathrm{C}$, por $3 \mathrm{~h}$. Amostras de material não polimerizado foram imersas em acetona e clorofórmio para a remoção da parte orgânica. As partículas de carga remanescentes foram cobertas com uma camada de ouro para avaliação da sua morfologia e tamanho, em microscopia eletrônica de varredura. O material Flexitime Denso foi o material com maior fração volumétrica de partículas de carga, enquanto que o Impregum teve menor fração volumétrica. Silon 2 APS Fluído apresentou partículas de carga de menor tamanho, enquanto que o Clonage Denso apresentou as maiores partículas. A observação em MEV. mostrou partículas de carga com vários tipos de morfologia (esféricas, irregulares, semi-esféricas, retangulares e mistura de retangulares/irregulares). Os resultados desse estudo mostraram diferenças nas partículas de carga dos materiais, as quais podem levar a diferentes resultados em suas propriedades mecânicas.

\section{ACKNOWLEDGEMENTS}

The authors would like to thank to the manufactures for supplying the materials tested.

\section{REFERENCES}

1. Anusavice K. Phillips' Science of Dental Materials. 11 ed. Philadelphia, PA: Saunders; 2003.

2. Chen SY, Liang WM, Chen FN. Factors affecting the accuracy of elastometric impression materials. J Dent 2004;32:603-609.
3. Melilli D, Rallo A, Cassaro A, Pizzo G. The effect of immersion disinfection procedures on dimensional stability of two elastomeric impression materials. J Oral Sci 2008;50:441-446.

4. Giordano R, 2nd. Impression materials: basic properties. Gen Dent 2000;48:510-516.

5. Mandikos MN. Polyvinyl siloxane impression materials: an update on clinical use. Aust Dent J 1998;43:428-434.

6. Kang AH, Johnson GH, Lepe X, Wataha JC. Accuracy of a reformulated fast-set vinyl polysiloxane impression material using dual-arch trays. J Prosthet Dent 2009;101:332-341.

7. Stober T, Johnson GH, Schmitter M. Accuracy of the newly formulated vinyl siloxanether elastomeric impression material. J Prosthet Dent 2010;103:228-239.

8. Craig RG, Sun Z. Trends in elastomeric impression materials. Oper Dent 1994;19:138-145.

9. Lu H, Nguyen B, Powers JM. Mechanical properties of 3 hydrophilic additijton silicone and polyether elastomeric impression materials. J Prosthet Dent 2004;92:151-154.

10. Adabo GL, dos Santos Cruz CA, Fonseca RG, Vaz LG. The volumetric fraction of inorganic particles and the flexural strength of composites for posterior teeth. J Dent 2003;31:353-359.

11. Lang BR, Jaarda M, Wang RF. Filler particle size and composite resin classification systems. J Oral Rehabil 1992;19:569-584.

12. Corso M, Abanomy A, Di Canzio J, Zurakowski D, Morgano SM. The effect of temperature changes on the dimensional stability of polyvinyl siloxane and polyether impression materials. J Prosthet Dent 1998;79:626-631.

13. Tjan AH, Li T. Effects of reheating on the accuracy of addition silicone putty-wash impressions. J Prosthet Dent 1991;65:743748.

14. Lawson NC, Burgess JO, Litaker MS. Tensile elastic recovery of elastomeric impression materials. J Prosthet Dent 2008;100:29-33.

15. Bold HC, Wynne MJ. Introduction to the algae. 2nd ed. Englewood Cliffs: Prentice-Hall, Inc.; 1985.

16. ISO 4823:2000. Dentistry - Elastomeric impression materials. International Organization for Standardization 2000:38.

17. Abdelaziz KM, Hassan AM, Hodges JS. Reproducibility of sterilized rubber impressions. Braz Dent J. 2004;15:209-213.

18. Balkenhol M, Haunschild S, Erbe C, Wöstmann B. Influence of prolonged setting time on permanent deformation of elastomeric impression materials. J Prosthet Dent 2010;103:288-294.

19. Brown RL. An elastomeric impression material breakthrough. Dent Today 2009;28:118-120.

Accepted November 4, 2010 